\title{
Accusation Theory
}

\author{
Jan A. Bergstra \\ janaldertb@gmail.com \\ Minstroom Research BV Utrecht, The Netherlands
}

\author{
Marcus Düwell \\ mduwell62@posteo.net \\ Institute for Classics and Philosophy, University of Bamberg, Germany \\ Submitted: 11 May 2021 \\ Revised: 30 November 2021
}

\begin{abstract}
Accusations play a pivotal role in human communication, including in contemporary political affairs. However, there is a lack of a philosophical conceptualisation that is necessary for appropriate descriptions of accusations and further philosophical scrutiny. Accusation Theory is proposed as such a theoretical framework. This paper (1) aims to present some general tools for the description of accusations as speech acts, (2) tries to understand fundamental features of accusations, (3) analyses some elements of the practice of accusing, (4) presents a short overview of relevant literature and (5) outlines some possible avenues of further research.
\end{abstract}

\section{Introduction}

Accusations nowadays stand out as a major class of speech act. While that may be true for human communication in general, there are indications that the role of accusations is increasing or at least changing. Reasons for this development may be multifarious. It is surprising that half of the Republican electorate in the US appear to believe that the Democrats stole the election in 2020, while none of the accusations were approved in any court trial. Is the formulation of an allegation sufficient for the creation of credibility? We will discuss more examples below but this example may suffice to justify our interest in the phenomenon. This is done through the medium of Promise Theory, which seeks to totalise the concept of a promise so that it applies to all possible promisers.

Claim 1.1. Accusations are ubiquitous. They play and have played pivotal roles in many social and political events.

Now cars are ubiquitous too and we do not wonder about the absence of a substantial philosophy of cars. Accusations, however, seem to play a constitutive role in human communication and for that reason are definitely worth academic and, specifically, philosophical attention.

Claim 1.2. The concept and practice of accusation has received remarkably little attention in philosophy and relatively little attention in various social sciences as well.

(C) Jan A. Bergstra \& Marcus Düwel 2021

Licence CC BY-SA 4.0 
Once accusation is coined as a key philosophical notion worthy of systematic investigation, one will predictably find that a plurality of different meanings may be attached to that term. The related concept, blame, comes with so many different interpretations that it is hard to make a justified choice for any of those, see [53]. Our angle is now, not to introduce a full-blown theory of accusation, because it is even unclear what such a theory would entail, since one can address accusations under a huge variety of questions. We will rather start with proposing some formal distinctions that allow us to provide the basis for appropriate analysis of accusations as speech acts and for further philosophical investigations. We will make use of conceptual distinctions that were developed in another context, namely Promise Theory. Promise theory is reviewed in Section 1.2 below.

Claim 1.3. A general theory of accusation may profit from a framework inherited from the framework of Promise Theory: initially only agent roles and aspects of content are distinguished and are provided with labels and names:

(i) accuser: a (human) agent, a group of (human) agents, perhaps an institution represented by one or more human agents (in principle this could as well be a non-human agent like God, devil or a machine),

(ii) accusee (accused) possibly a plurality of accusees: one or more agents, which may also be institutional, and which may be animate, human or non-human, as well as inanimate, including human developed artefacts,

(iii) accusation body: text, content, which is communicated and may also be stored in some form, scope of the accusation (one or more accusees),

(iv) life cycle: understood as a speech act, it may be equipped with time and place of being made, and it may expire at some moment in time. At various stages of the life-cycle, an accusation may be repeated, and it may be modified, accusees and scope may be modified as well. Whether or not an accusation is a new one, or is a repeated instance of an existing one, is a matter of ad hoc judgement.

In Promise Theory artificial agents are analysed as promisers and promisees. But it is not obvious that this is fruitful for accusations as well. There are examples of non-human accusers and accusees (in Stanley Kubrick's '2001: A Space Odyssey', the Computer HAL accuses a human being; in the Bible, Job 3, accuses God), but, for the moment, we will start with the assumption that accusers are essentially human. For an accusation to take place, or to have taken place, each of these aspects must have a clear interpretation.

Suppose A states: "someone has stolen my car". This is an accusation with, initially, everyone (including A themselves) as an accusee, while, during the life-cycle of the accusation, more and more persons are considered non-accused.

In what follows, we will (1) introduce basic terminology and explain the aim of our investigation, (2) propose an initial understanding of accusations, (3) present first considerations regarding the practice of accusations, (4) have a short look at the existing literature and (5) mention possible further topics for investigation. It should be mentioned that we try for the context of this paper to be as general as possible. We are fully aware that there are very relevant distinctions (like accusations in court vs. in everyday conversation, legal vs. moral understanding of accusation etc.) that we will not engage with. This does not mean that we find them not relevant; quite the opposite. But we think that all those further investigations are only possible after scrutinising some basic conceptual questions. We will therefore develop a concept of accusation at such a fundamental level that our considerations will be relevant for all of those further areas of investigation.

\subsection{Subject matter of accusation bodies: accusation versus praise}

It is the accusation body which differentiates between promises, accusations and threats. Without claiming completeness we can observe the following characteristics for accusations: 
- It is primarily the accuser who assigns the label "accusation" to the content of a body. This is often done implicitly. Thus agents in scope or accusees have to know the perspective of the accuser in order to determine whether or not an accusation is made.

- By being situated in another context, a promise or threat may turn into an accusation, and the other way around.

- The opposite of accusation is praise, which is a speech act that expresses admiration.

- Precisely the same body may constitute an accusation for one accuser and praise for another "accuser".

- When comparing the standard communicative strategies in which accusations, praises, promises and threats are embedded, we find some informative differences: we can interpret 'A issuing a promise to B' in the way that 'A intends to support B in achieving B's objectives'. Within the normal communicative logic of promises to speak about a promise will entail the assumption that 'B promises A that B will accept this support'. This combination of two voluntary promises constitutes a communicative mechanism which can be called 'two way voluntary cooperation'. It is primarily in the frequent establishment of such pairs of promises where the communicative role of promises lies. Here lies the original rationale for promising, even if promises can be used outside that rationale (e.g. if the Mafiosi says: 'I promise to kill you'). For threats it is the other way around, the threatener issues a threat in order to discourage the target of the threat from pursuing certain objectives. Thus, it is constitutive for the communicative role of promises and threats that they relate (positively or negatively) to the purpose-pursuing of the promisee or the person under threat. Complementary to both proper promise and threat there is imposition, an imposition is a promise which indicates how the promisee may be helpful for the promiser, though without promising anything in return for that help when provided.

If we would take accusation and praise as forms of promises, would we find a similar mechanism? Accusation and praise are discerned primarily by the polarity of promiser's intentions. If the promise expresses some form of compliance with the promiser's views or intentions, the promise may be considered praise, and if the promise gives expression to a mismatch between a state of affairs due to the target it may be considered an accusation. The intention of the promiser is thus in fact more important for contrasting accusation with praise for contrasting promise with threat.

- Accusation, praise, and dispraise share the triple and mutually independent dichotomy of scope inclusion:

(a) (Target inclusion versus target exclusion.) The target of praise/accusation may or may not be included in the scope of it.

(b) (Private assessment versus public assessment.) The praise/accusation may primarily express the issuer's viewpoint or feelings about a past, current or future state of affairs, supposedly due or partly due to the source, or it may primarily rest on the expected judgement of agents in scope of the underlying promise.

- Some characteristic dichotomies are shared by (proper) promise, threat, imposition, accusation, and praise: (i) (Witnesses in scope.) The dichotomy between the presence or absence of external (that is, non-target) agents in scope is a feature of (proper) promise, threat, imposition, praise, dispraise, and accusation alike.

(ii) (Sincerity.) The speech act may disclose true opinions and feelings of the source, or it may be quite the opposite: a hard to discern fake, intended to mislead the target or one or more agents in scope or both. 
(iii) (Reproducibility.) It may or may not be difficult for various actors to prove that the specific promise was made.

- So A may praise B (in public, that is, to the agents in scope) for having been very helpful to A (in a manner which is intentionally not disclosed to the public, that is a matter of private assessment).

\subsection{From promises to accusations}

We insisted on the comparison between the four types of speech acts because we expect that the tools of Promise Theory can be helpful for the further analysis of the logic of accusation. Promise Theory was designed by Mark Burgess in a series of papers from 2005 onwards. See also: http://markburgess . org/treatise.html for introductory material. For a survey of this work and extensions of it see Burgess 2015 [19] and the more technical exposition in Bergstra \& Burgess 2014 [10]. Promise Theory is claimed to be of use in the context of informatics, see e.g. Bergstra 2020 [7], Bergstra 2020b [8], Bergstra \& Burgess 2019 [12, 13] and Bergstra \& Burgess 2020 [14]. Within informatics, Promise Theory allowed for a description and reconstruction of the internal logic of different communicative moves in which promises play a crucial role. Moreover, Bergstra \& Burgess 2017 [11] and 2020 [12] both provide extensive case studies for Promise Theory outside the realm of informatics. It appears that Promise Theory is helpful for understanding systems of animate agents as much as it is for specifying systems consisting of inanimate agents.

Accusation and promise share a typing framework. Where Promise Theory adopts the notion of a promiser, Accusation Theory adopts the notion of an accuser. Where Promise Theory adopts the notion of a promise body, Accusation Theory adopts the notion of an accusation body. Promise Theory works with the notion of a promisee, and in some cases of a plurality of promisees, Accusation Theory uses the notion of an accusee, and in some cases of a plurality of accusees. Both Promise Theory and Accusation Theory maintain a notion of scope, that is, the collection of agents who are supposed to be notified of a promise in case of Promise Theory, and of an accusation in case of Accusation Theory. A promise can be prospective (the most common case) or retrospective, an accusation is often retrospective but may be prospective.

As an example of a prospective accusation we mention president Trump's claim, repeatedly made in advance of the 2020 presidential elections that his opponents will commit significant voting fraud ([52]). Another prospective accusation has been, in advance of the invasion of Iraq, that the late president Saddam Hussein intended and planned to develop and deploy weapons of mass destruction (see [46]).

Promises as well as accusations constitute speech acts, or an abstractions thereof. This quality accusations inherit from promises, and "speech act strength" may imply that upon being repeated an accusation undoes its own novelty in due course. An accusation may introduce a conflict between accuser and accused, it may force or invite agents in scope to choose sides, it may impact on the subjective belief agents in scope maintain about accusations and blame assignments which were uttered before.

Insisting that an accusation is an event involving spatial and temporal coordinates may be impractical, in which case some of these coordinates may be ignored or omitted when making reference to an accusation. In such case the idea is that these coordinates are implicitly present and can, wen required, be reconstructed in an unambiguous manner.

Like with a promise, it is assumed for an accusation, that the accusation is made by an accuser at some time and place, and that it persists with those qualities. In particular an accusation is time stamped so that, for instance, novelty and truth may be determined relative to the time stamp.

Promise Theory exploits the unconventional idea that by default a promise will not come necessarily with the willingness of the promiser to keep the promise to the promisee. This assumption constitutes a simplification by rendering promise independent from obligation. Scanlon 1990 [49] provides some insight 
in how the complex interdependence between promise and a plurality of meanings of obligation may impact on one's understanding of promises.

\subsection{What kind of theory are we looking for?}

Is this section we collect some general observations on what to expect from an accusation theory, by first contemplating the existing theory of blame.

\subsubsection{A theory of blame exists, are we looking for a similar theory?}

An extensive literature has been written about blame, much more so than about accusation. An introduction to "blame' is given in Tognazinni \& Coates 2018 [53]. The term blame has so many nuances and different interpretations that systematic use of it must be preceded with an explanation of the approach to blame.

We will mention one example of such theories only. Malle, Guglielmo and Monroe 2014 [37] provide an extensive theory of blame. They view blame as a psychological phenomenon concerning the process of arriving at a judgement of blame by an individual, or as a social phenomenon when a focus lies on the effects of a blame judgement. Linguistic analysis provides a meaning for blame, which then allows differentiation between wrongness judgement, event evaluation, and anger. A key feature of blame is a warrant, a justification of the blame judgement by agents making that judgement.

Having made demarcations of surrounding notions, remarkably not including accusation, the authors present the so-called path model which specifies an order of mental information processing steps as performed by an agent which may, or may not, lead to the production of a blame judgement by that agent.

Besides psychological aspects of blaming with a focus on how an agent arrives at a blame judgement in the first place, the social dimension of blaming is also about expressions of such a judgement. The authors consider two cases: (i) persuasive blaming where the blamer directly confronts the offender (the agent being blamed) with the blame judgement, and (ii) third party blaming where other agents than the offender are informed about the blame judgement against the offender. In both cases a warrant is said to be needed.

Social blaming comes close to accusation. Differences between blame and accusation are at least these: (i) blame typically concerns an action said to have been performed by the offender (the subject of blame), (ii) a blamer believes their value assignment, (iii) blame requires warrant, (iv) blame is connected with an assessment of intentionality at the side of the offender, as well as with awareness of the blamer of some degree of intentionality.

We will assume the following definition of blaming, which is merely a choice from many options:

Definition 1.1. Agent $A$ is blaming agent(s) $B$ if $A$ maintains the judgement that actions by $B$ have caused (perhaps among other causes) the coming about of a state of affairs which A considers wrong.

However, it may be questioned whether this minimal definition suffices. One can at least wonder whether blame does not entail at least some awareness on the side of the offender for the negative outcome of their action.

\subsubsection{Looking for a type and structure sensitive general logic of accusation}

Our theory of accusation aims to provide in first instance a conceptual outline, with accusation understood as a logical notion, that is, a philosophical concept. Thus, we neither aim at a psychological or sociological analysis of 'accusation' nor at an ethical or legal approach of how to deal with accusations but we assume that the logic of accusations should be investigated in advance of psychological or sociological investigations, 
even to be able to identify accusations in the first place. Type and structure appear if one contemplates the following questions: (i) whether or not an accusee is in scope (in a particular case), (ii) or if accusations are transitive (under certain assumptions), or (iii) if one contemplates the possibility that the accuser and accusee are the same agent.

We look for maximal generality, hoping to accommodate different views of accusations as different special cases of the general conceptualisation of accusation from which a plurality of features is inherited. Generality is first of all achieved by doing away with potential limitations.

Hypothesis 1.1. Issuing an accusation does not necessarily come with the willingness of the accuser to demonstrate the validity of the accusation body.

We do not assume that the accuser necessarily sees himself under the imperative that accusations must be substantiated. Note: we do not claim here that the accuser does not have reasons to see himself under such an imperative and that others are not legitimated in expecting such a demonstration from him. Rather the claim is that it is neither constitutive for an accusation that the accuser has that willingness nor that others can presuppose this willingness.

Hypothesis 1.2. Issuing an accusation does not create a promise by the accuser to demonstrate the validity of the accusation body.

The following far reaching claim is suggested as consequence from this. An original accuser is defined as an agent who initiates an accusation on the basis of their own knowledge and/or experience.

Claim 1.4. Accusations play a major role in complaint mechanisms. The very option to raise complaints and see these discussed is an essential feature of social life. This feature is complementary to the principle of voluntary cooperation. Because of the central role accusations play in social life, it is implausible to assume that only those complaints count as accusations that come with the willingness of the original accuser to substantiate the claims on which the accusation is based. However, a basic feature of accusations is the willingness of the accuser to acknowledge to having originated the accusation.

Claim 1.4 rules out the spreading of gossip as an instance of accusation, which is our position. Spreading gossip may be understood as a method or mechanism for creating incentives for other agents for issuing accusations.

\subsection{Coexistence of static and dynamic semantics, with a static bias}

An accusation may be understood as an action performed by an agent at a specific moment in time. Doing so assigns dynamic semantics to the accusation.

Alternatively an accusation may be understood as the (typed) content of the body of the accusation (understood by way of dynamic semantics) which persists in time (unlike the act of accusing which need not last very long).

By default we will maintain a static view on accusations: an accusation is a piece of content about which various questions can be asked: who made the accusation and when (and who was in scope at that time), when was it made for the first time, is the accusation the residual form of a previous accusation, to which original accusation can this accusation be traced back, do we expect the accusation to be issued once more in the future, how well spread is awareness of the accusation.

With a static view on accusations we do not imply that accusations cannot change but that it is the succession of relatively stable states that exist in time which matters more than the specifics of time place and cause of change of an accusation. 


\section{What is an accusation? Consulting Wikipedia to begin with}

Wikipedia provides the following definition of an accusation (https://en.wikipedia.org/wiki/ Accusation as available on 22-11-2020):

(For other uses, see Accusation (disambiguation)). An accusation is a statement by one person asserting that another person or entity has done something improper. The person who makes the accusation is an accuser, while the subject against whom it is made is the accused. Whether a statement is interpreted as an accusation relies on the social environment in which it is made [51].

What counts as an accusation is often unclear, and what kind of response is warranted even less clear. Even a purely surface semantic analysis of accusatory language cannot be performed in the absence of social context, including who is making the accusation and to whom it is being made - often the subject of supposedly accusatory language might well interpret the utterance in question as something that he need not respond to [51]. An accusation can be made in private or in public, to the accused person alone, or to other people with or without the knowledge of the accused person. An accuser can make an accusation with or without evidence; the accusation can be entirely speculative, and can even be a false accusation, made out of malice, for the purpose of harming the reputation of the accused.

In a further comment the same Wikipedia entry asserts

...As noted, an accusation is an early warning, a danger-ahead signal of trouble. And it involves a redefining of the situation to find out not only what the wrong is, but also who is wronged and by whom. Inevitably, in this event-defining process the accused becomes an archetypal betrayer....

\subsection{Criticising an initial definition}

Now there are these comments to be made:

(i) an accusation can be made regarding a group of individuals or an organisation, instead of a single individual as the accused. The comments in the Wikipedia entry indicate that the latter was meant,

(ii) we prefer (following Promise Theory) to include the scope (audience) as a part of the notion being defined since this enables us to scrutinise the content of the accusation in more detail, and

(iii) it is not obvious that the accused must have "done" something. For instance the following accusations are not about an action of the accused: $B$ got the academic position now held on the basis of a fraudulent procedure", " $B$ was awarded a prize while the committee knew already that the novelty of $B$ 's work was contested (at a moment such facts were not yet known to $B$ )", " $B$ has been accused of personal harassment by $C$, a state of affairs for which no proof can be given.

(iv) The aspect of novelty, or being contested is missing from the definition. The requirement of novelty merits illustration by an example: an assertion to the extent that "the US have been accused of using nuclear weapons against Japan" is likely to be met with disbelief. As if there have ever been any doubts about the matter of fact which would justify speaking in terms of an accusation. Thus, we assume that we normally only speak about an accusation as long as the matter is not settled but under investigation or contested. 


\subsection{What is an accusation? Proposal for a definition}

In Bergstra [9] a theory of threats is put forward based on the assumption that a threat is a special case of a promise. (For an original account of threats we mention [4].) Similarly one can claim that accusations are instances of promises.

Definition 2.1. An accusation is an instance of a promise which meets some additional constraints:

1. (renamed terminology) the promiser is called accuser, the promisee is called accusee (or alternatively: accused), the promise body is called accusation body. However, just as a promise need not be explicitly labeled (typed, qualified) as promise an accusation need not be explicitly labeled as such either (so it may be the case that a person issuing an accusation is unaware of that fact, or disagrees with it, similarly an accusee need not be aware of being accused).

A self-proclaimed accusation is an accusation where the accuser explicitly qualifies the body of the promise as the content of an accusation. So we propose to assume by default that an accusation is selfproclaimed. This is a difficult matter because it opens the door to claiming that a promiser has issued an accusation in a case where they intended to produce an act of praise instead. This situation can only be avoided by assuming by default that all accusations are self-proclaimed. We suggest that the assumption of accusations being self proclaimed is a matter of context dependent rules of engagement about accusations.

2. (negativity) by the very event of the promise body being communicated to agents in scope the promisee $i$ at risk of a degradation of its reputation among the agents in scope,

3. (deniability) the promise body involves an assertion which, at least in principle, the promisee might deny, in which case the denial would itself be a promise as well, and more likely than not itself be considered an accusation. Deniability is a weaker requirement than refutability, in other words an irrefutable (promise) body may still be deniable.

4. (impact potential) in case of a very limited scope (possibly consisting of the promisee only) the promise body may have an intimidating effect on the promisee (either by indicating why the promiser may seek for revenge, or by indicating that the promiser might engage in some kind of blackmail, or by negatively affecting the promisee's self confidence),

5. (novelty) the promise body involves some novelty (for a significant fraction of the agents in scope, often not for the accusee, in particular not if the accusation is valid) to the extent that its validity has not yet been confirmed by means of procedures which may be supposed to meet general approval among the agents in scope of the promise.

6. (being contested) in the absence of novelty, the promise must not simply qualify as a promise of fact, and instead (again writing from the perspective of the agents in scope) the promise body must somehow be essentially contested.

The negative connotation or meaning of the body may be a contextual matter, that is, taken outside its context it may be impossible to even see that a promise body meets (i), (ii), and (iii) above. Novelty may also be context dependant. Even if a court has judged that an accusee is guilty of the accusations against them, that very judgement may not be appreciated within a community to the extent that within said community the accusations at hand still meet the requirement of novelty. 


\subsection{Properties of accusations}

Besides the defining criteria mentioned in Definition 2.1 an accusations may have various further properties:

1. (hidden) an accusation is hidden if the accusee is not in scope, otherwise it is overt.

2. (confirmed) an accusation is (that is, has been) confirmed if trusted fact finding has established the validity of its body.

3. (formally confirmed) an accusation is (that is, has been) formally confirmed if a potentially flawed but technically as yet uncontested process of fact finding has established the validity of its body. (For instance an accusation of plagiarism has been confirmed by a committee that has been set up in an appropriate manner within an institution, but in such a manner that the committee contains personal enemies of the accusee).

4. (disconfirmed/rejected) an accusation is (that is, has been) disconfirmed (rejected) if trusted fact finding has established the invalidity of its body.

5. (formally disconfirmed/rejected) an accusation is (that is, has been) formally disconfirmed (rejected) if a potentially flawed but technically as yet uncontested process of fact finding has established the invalidity of its body. (For instance an accusation of plagiarism has been rejected by a committee that has been set up in an appropriate manner within an institution, but in such a manner that the committee contains personal friends of the accusee).

6. (confirmability) an accusation is confirmable if in principle, and in practice, it can be determined whether or not its body is valid.

7. (refutability) an accusation is refutable if a proper process may confirm or refute the validity of its body.

8. (fully target specific) an accusation fully target specific if it is precisely known and clear who are the accusees of the accusation.

9. (anonymous targeting) an accusation features anonymous targeting if the accusee is unknown (for example, it may be alleged that a death is not innocent but that instead some unknown person has murdered the deceased).

10. (class targeting) an accusation involves class targeting if its accusees are a not yet specified subgroup of a class of agents. (Some prison staff, not yet known who, have helped the defendant to escape.)

11. (fuzzy class targeting) an accusation is fuzzy class targeting if its accusees are a not yet specified subgroup of a vaguely defined class of agents. (For instance: "someone from the Amsterdam drug scene has committed this crime".)

12. (retaliation readiness) an accusation is retaliation ready if (i) it has been refuted in court, (ii) it is fully target specific, and (iii) one or more of the accusees may file a potentially very successful complaint against the accuser on the basis of reputational damage which is claimed to be incurred by the accusee.

13. (retaliation sensitivity) an accusation is retaliation sensitive if (i) it is likely to be refuted in court when properly investigated, (ii) it is fully target specific, or after some reprocessing it can be made fully specific, and (iii) one or more of the accusees may file a potentially successful complaint against the accuser on the basis of reputational damage which is claimed to be incurred by the accusee. 
14. (Fact and norm depend on scope) One may hold that an accusation combines cognitive (factual) aspects with normative aspects. Both aspects, however, depend on who is in scope of the accusation. We mention two examples:

(i) $p \equiv$ " $A$ accuses (male) $B$ of "being homosexual", with scope $S$ ". In this case it will depend on the audience to which extent $p$ constitutes an accusation. This may also depend on the jurisdiction, and within a fixed jurisdiction changing law may turn $p$ from being an accusation to not being an accusation, and conversely.

Given a jurisdiction in which, with all members of the jurisdiction in scope $p$

(ii) $p \equiv$ " $A$ accuses (female) $B$ of "being tolerant of abortion", with scope $S$ ". In this case it depends on the audience to which extent $p$ constitutes an accusation. This may also depend on the jurisdiction, and within a fixed jurisdiction changing law may turn $p$ from being an accusation to not being an accusation, and conversely.

\section{On the practice of accusation}

Thus far we developed the technical preconditions for an appropriate analysis of accusations. In what follows we will discuss some aspects of the practice of accusation and will start with the example of an accusation we mentioned already in the beginning of the paper. In November 2020 president Donald Trump accused the democratic party of having stolen the election from him. (See [56] for further information on these quite controversial matters.) Various attempts to challenge the democrats in lawsuits were not successful because the Trump-team could not (at that time) present sufficient evidence that the accusation was valid.

Moreover, Trump started to accuse his political opponent already months before the election. This accusation preceding the actual event of wrongdoing is, however, not a proof of the prophetic capacities of the (then) president of the United States but rather an element of a well-orchestrated campaign resulting in the fact that in December 2020 half of the Republican electorate actually believed that the democratic candidate Joe Biden stole the election (see e.g. [34] for this accusation and its historical context). The accusation formed furthermore the justification for the storming of the US Capitol Hill on January 6, 2021, see [2] and [34].

One can of course speculate whether this behaviour reveals specific Machiavellian strategies or abnormal character traits of Trump or claim that this is an atypical way of using accusations. We hold however, that there is nothing atypical in the way Trump uses "accusations". We will then reflect a bit more in detail about the "nature" of accusations. Our claim is that accusations can have different functions within different normative orders. That has some implications, and we should deal with applications and see their status. We are aware that the social function of accusations is undergoing significant changes in times of 'social media'. The dynamics of accusations, counter-accusations, the institutional setting and other factors change at a rapid speed. But this paper is primarily interested in the theoretical outlook of the problem of developing a theory of accusations and will neither go into the details of those social functions nor an extensive normative assessment of how within an open societies accusations should be handled. After a first review of the literature (and the consultation of experts from various disciplines) we found that a lot of discussion are directly focusing on phenomena like "false accusations" or procedures of how to determine the legitimacy of accusations. By doing so the very question what characterises an accusation is bypassed. For example, it is problematical to distinguish between 'accusations', 'slander' and 'rumour' because it is very possible that A accuses B with the intention to spread rumour about B. Whether or not this is the case can only be decided after scrutinising the accusations and not beforehand (in some cases it cannot be decided at all). We think therefore that it is more productive to treat 'accusation' in the first instance as a more 'generic' term and to 
reflect systematically on the different functions accusations may have and to justify explicitly how we deal with accusations in a normative perspective.

If we look on Trump's accusation regarding the stolen election we can find at a first glance three characteristics which are remarkable but not really surprising within the outline we made above. We think that these elements can be observed quite often:

(1) Accusing does not necessarily come with the willingness to present evidence for the legitimacy of the accusation.

(2) Accusations can in some cases persist in spite of a lack of institutional validation.

(3) Accusations are possible regarding future actions.

\subsection{Examples of accusations}

Let us first look for some examples of accusations:

1. "Death spread to all men because all sinned." (Paul, letter to the Romans 5,12).

2. "Men are such pigs" (German pop band Die Ärzte: Männer sind Schweine).

3. "You are a millionaire paid by billionaires" (Rutger Bregman to Tucker Carlson).

4. "All Politicians are corrupt".

5. "John F. Kennedy was assassinated by the CIA".

6. "You destroyed my entire life" (people after a divorce).

7. "You will end-up as a criminal if you even grown up".

8. "You would even do harm to your grandmother, if you thought it would advance your career".

9. "A has murdered B in Central Park on Friday 13, 2020 at 6 p.m."

10. "You are far too rich".

11. "He is a horse thief, hang him up".

12. An outrageous accusation towards a specific person for instance see [57].

We guess that these are a kind of accusations that everybody will have heard in one way or the other. We can observe the following features:

- Accusation can be quite specific regarding the content of the accusation and the circumstances (9) but likewise they can be extremely unspecific in scope $(1,2,4)$.

- Accusation can rely on facts that are contested (5) or uncontested (3).

- Even if the facts are uncontested, the normative standards underlying the accusation can be contested $(3,10)$.

- Accusations are possible for which any empirical verification or falsification is impossible, either for principled reasons $(1,2,4)$ or because most of the potential accusers have not sufficient access to the relevant information (5). 
- Accusations about future events are possible $(7,8)$.

- Accusations can articulate general views on the human condition $(1,2)$.

- Accusations can be a direct request for action without expectation of a validation procedure (11).

The above list of observations is by no means exhaustive. But already a first reflection on accusations supports the impression that Trump's accusations are not at all atypical but fully in line with accusations we find in everyday conversation. This is a reason to specify the concept of accusation on a generic level and to demarcate accusations from other phenomena.

\subsection{The concept of accusation: accusation as a social phenomenon}

Accusation can in some sense just be seen as a strategy of organising social relationships and to create some form of social dynamics. We can analyse accusations in terms of the effects that accusers expect them to have or in terms of further argumentative or strategic moves that are socially expected from the accuser or accusees. Those aspects can differ significantly in different cultural and normative systems. The selfunderstanding of the accuser or of the accused can differ and likewise expectations of what a proper response to an accusation should be can differ. If, while drinking in a pub, one accuses politicians of being corrupt, the accuser just articulates his outlook on a certain aspect of the world. He does expect full agreement from his peers and he does not see himself in the position to give any justification for his claim because what he articulates 'feels natural'. Or if in the Wild West someone was accused of horse theft, there would not necessarily be an expectation of further scrutiny but accusation, condemnation and punishment would be seen as hardly distinguishable activities. Those differences depend on a variety of aspects:

First, the method of expected validation procedure regarding such an accusation can be different.

Second, there can be differences regarding the question whether or not an accusation is expected to be validated in the first place. If, in a small village, the owner of the local grocery store spread the rumour that a member of the village has an extramarital affair, a lot of customers may expect a specific form of entertainment by rumour while they neither expect an empirical justification for the truth nor are they in any way interested in such a justification (the accused may have a different view on this).

Third, in some contexts accusations can be understood as a function of specific actions of an individual and sometimes accusations are just the articulation of a generic expectation concerning a specific group. For example, when accusations are primarily or exclusively repetitions of specific stereotypes about certain (racial, ethnic, societal) groups, such as 'all politicians are corrupt'. The underlying assumption is rather that the accusation describes types of action that are normally taken by specific collectives because of typical character traits of this collective.

These are only some of the relevant factors but the short list shows already that Trump's accusations are perfectly possible. If an accusation is understood as the description of a type of action that are normally performed by democrats ('stealing elections') the expectation is not that such an accusation needs to be justified by means of empirical facts. And if in the view of the accusers this type of activity ('stealing elections') follows from the very nature of what it means to be a Democrat there is no reason whatsoever to wait until they really stole the election before accusing them of this, we can know 'a priori' that the predicate 'stealing the election' is a necessary implication of the predicate 'being a Democrat'. From the perspective of the accuser the only question remains: What rhetorical effort is necessary from me to have the rhetorical effect that people really believe the accusation?

A further complication may be that in some communities conspiracy thinking has reached a certain level of general acceptance that it is not expected that access to reliable information is possible in the first place. 
If one believes that all sources of information are manipulative, the entire concept of empirical justification is not applicable. In such contexts, it does not feel strange to believe that Hillary Clinton is running a ring of Paedophiles in the basement of a certain Pizzeria. See [1] for more information on so-called PizzaGate.

So far, we primarily dealt with the question whether or not to accuse someone comes necessarily with the willingness to provide evidence that the content of the accusation really happened. But accusations are not just reporting events, they are at the same time evaluations of those events, so they carry the judgement that an action is in some sense bad. Thus the logic would be: Organising a paedophile ring is bad and it reveals the badness of the character of Hillary Clinton that she is involved in such things. Perhaps the reasoning runs the other way around: because we know that Clinton is a bad person, it is natural that she is involved in those activities. Accusing someone of something does not have to come with the willingness to give a justification for the validity of the normative presuppositions. In a rhetorical sense it is even more effective if we can accuse someone of something where it is normatively uncontested that this behaviour is bad. This is, however, not always the case. There can be severe normative disagreement about whether or not euthanasia or abortion is wrong or not. And respectively, the statement 'you were involved in aborting an embryo' can be an accusation of a wrongdoing or the information that you were willing to help a person in a difficult situation.

To sum up: Relevant for our context is the insight: 'A accuses B of bad action X' does neither require the willingness of A to justify empirically that ' $B$ really did $X$ ' nor to give arguments why ' $X$ is bad'. Within social interaction it is perfectly possible to assess accusations under the perspective whether they are effective strategies to make people believe something or to motivate them to act in specific ways. And in that regard, one has to concede that Donald Trump is in some sense successful if he made millions of people believe that Joe Biden stole the election and persuaded some to storm Capitol Hill to prevent this crime from happening. We claimed that accusations can have different functions within different normative orders.

\subsection{Accusations as a carrier for the scapegoat mechanism}

We only want to refer to one specific normative perspective in which accusations play a central role in order to demonstrate that the effects of accusations are far from self-evident: The scapegoat mechanism, has been elaborated by the anthropologist René Girard as an outline of a social mechanism in which accusations play a central role (we owe this example to Gesa Lindemann [36] where reference is made to Girard [27]). It does not matter for this purpose whether or not his specific analyses are empirically accurate, it is only relevant to understand the mechanism as one model for a possible functioning of accusations. Within the logic that is reconstructed by Girard, it is important for the stabilisation of a normative order to sacrifice a scapegoat once in a while. The sacrifice unities the community among a joint normative idea. The normative order along the scapegoat-model presupposes that human beings are in principle replaceable. For the stabilisation of the normative order it is not relevant who is sacrificed, what counts is rather that the normative order is stabilised and symbolically affirmed. Typical examples for such scapegoats are witches, Jews, homosexuals, whoever is an appropriate target. In general, a scapegoat is chosen that can fulfil this function effectively the chosen targets have often some weakness that make it easier to offer them. Whether or not the scapegoat did something wrong is in such an order relevant only if the realisation of the offering requires it to address questions of accountability. But it is by no means intrinsically relevant whether or not the scapegoat did something wrong or did anything at all. Accusations are allowed to the extent that they are effective in identifying and offering a scapegoat and to stabilise a normative order. Nevertheless, some rhetorical effects can be required to convince the crowd that offering this specific scapegoat is appropriate. But from this perspective a lawsuit is as good a means for identifying the scapegoat as spreading rumours or deducing the guilt of the victim from a categorical imperative. As long as in the end there is a scapegoat that others are 
willing to sacrifice, all means are fine. In such a circumstance, accusations function only as means to enable the offering.

\subsection{Towards a a normative perspective of accusations}

The considerations so far could give reasons to be sceptical about the nature of accusations in general; accusations are a dangerous aspect of human communication. But at the same time, it seems obvious that accusations fulfil a central function in human life. If it is important for social life to have normative rules/normative principles (practical precepts of some kind), it must be important that agents confirm to these rules and principles. To be committed to some normative rule or principle means to care about its realisation. This implies that in some sense punishment is necessary in case of norm violations. A group cannot be neutral to a norm violation if it claims to be committed to these norms. This follows from the entire idea of being committed to a norm or a principle. But societies change in the ways of dealing with norm violations and stabilizing the normative order. In that sense, we can see 'open societies' as strictly opposed to scapegoat-societies. We understand here open societies as societies not in the sense of a specific philosophical conception (e.g. in the tradition of Karl Popper) but as a generic term for those societies that are committed to the rule of law, human rights, and democracy. We do not make any assumptions here that only 'Western' societies are 'open societies' and likewise not that all Western societies are open ones. We furthermore do not assume that there is a necessarily teleological development from a premodern scapegoat-society to a modern open society. It is in principle possible that a modern society falls back to the level of a scapegoat society - and maybe the Trump endeavour has to be interpreted as an attempt to reinstall a scapegoat society within the institutional frame of an open society. Within such open societies rights function as restrictions regarding the possibilities to articulate accusations and they as obligations for legal and political institutions to deal with such accusations These restrictions can have different forms, some of them will be more general restrictions, while others will be bound to specific institutional and social contexts. Restrictions concern (among others): topics about which one can legitimately accuse someone in public (for example, privacy constraints), there is a duty to regulate the normative criteria for what count as a wrongdoing for which agents can be accused (for example the rules must be public) and regulations regarding the duties of institutions to investigate accusations, the presumption of innocence and rights to defence on the side of the accused. Without going into details of those rights and regulations, we can say that having such regulations is indispensable for open societies, it is the heart of such societies.

\section{Existing work on accusations}

Fritz 2005 [25] provides a detailed definition of accusation. Fritz requires that the wrongdoing as (pronounced in the promise body) constitutes an act or state of affairs for which the accusee can be held responsible, (that is they could have done otherwise). We have not adopted this requirement. For instance $A$ may accuse (male) $B$ of owning works of art, which when $B$ was very young, $B$ had inherited from his mother, who in fact had obtained these particular works of art by theft, a theft which took place long before $B$ was born and which had been successfully kept secret until recently.

Pavlich [40] notes that the etymology of crime talk requires further attention. For instance accusation may be better understood as "holding someone to account for their actions", and the etymology of crime (crimen) is close to that of accusation. Further Pavlich suggests to free crime related terminology and process from too much realism. Perhaps by giving accusations more of an independent status the ideas of Pavlich become incorporated to some extent in Accusation Theory. 
Pavlich [43] uses deconstruction to obtain a critical account of the conventional role of accusation in legal processes, an approach which is, however, criticised in detail in [21]. Pavlich [42] positions accusation in the context of Foucault's notion of an avowal. This move is essential for an understanding of the context in which accusations that defeat simple fact finding operate. Pavlich [43] emphases that the history of accusation in Roman law gives it a much stronger position than merely expressing the assertion that a crime was committed. In contrast accusations were defining for the crime at hand. An accusation amounted to the request that the people, by way of the court, hold the accusee to account for what was done.

Finally Pavlich [44] presents the motivation of our work in a very convincing manner: accusations play a special role in restorative justice, and when things go wrong in terms of procedures a struggle may take place, there is no way around this. It is in the context of several struggles of this nature that the need for a better understanding of accusations arose.

In Hughes et. al. [32] accusations are considered from an anthropological perspective. Accusations may sometimes serve as an expression for underlying feelings and emotions which are considered less accepted vehicles for direct linguistic phrasing. For instance greed and anger may both trigger accusations. In comparison with this work our approach takes a more limited scope of meanings of accusations into account. Confusion may be avoided by means of some straightforward conventions: (i) Accusation Theoryaccusations are accusations as used in Accusation Theory, and (ii) in the context of a discourse involving accusations understood via Accusation Theory, accusation is a shorthand for Accusation Theory-accusation, (iii) the shorthand is merely a default and other classes of accusations may be used as well provided sufficient disambiguating information is given

In Pierce et. al. [45] accusations are mere assertions the truth of which is left untouched. The authors focus exclusively on how contextual factors influence the degree of belief various actors attach to an accusation. Merely the negative phrasing of an accusation justifies its classification as such.

Nicol 2016 [38] introduces the notion of a field of accusation, which is made up from a coherent constellation of accusations and counter accusations. She speaks of a blaming incident and statistically investigates a total of 5,712 blaming incidences during the financial crisis in the timespan 2007-2010. Although intuitively appealing the notion of a counter accusation is not easy to define. The simplest definition is that the roles of accuser and accusee have been switched and that there is comparable significance, while correlating the logic of the bodies of an accusation and a counter accusation is less plausible.

Webb 2015 [55] describe how, in the US, an accusation, once existing, will not go away and may give rise to repeated attempts to obtain a proof leading to a conviction. In particular failed attempts do not suffice to terminate the relevance and impact of an accusations.

In Javers 2014 [33] the case is made that near the end of the Qing Dynasty (ending in the beginning of the 20th Century), false accusations were used to make cases in court, and that it would not be unusual for the court to accept the false accusation as a trigger for formal proceedings, to ignore the falsity of the accusation, and then to rule on an underlying problem which was understood to be the real problem at stake. The author suggests that by taking on board false accusations courts strengthened their position.

Variations of the mechanism put forward by Javers may be present nowadays just as well, for instance in less formal procedures involving within a business context, where the penalty for a false accusation is low. A severe accusation may lead to an investigation which, although disconfirming the principal accusation, as an (intended side effect) generates the confirmation of a less significant accusation (which, however, in the absence of the principal accusation would not have attracted enough investigative energy to achieve confirmation).

Rudiak-Gould 2014 [48] provides an intriguing description of a case of self-accusation and self-blaming where in spite of ample evidence to the contrary for a certain class of agents self-accusation and self-blaming is a means to other ends quite remote from the subject (and validity) of the accusations. 


\subsection{False accusations}

The notion of a false accusation is both ubiquitous and puzzling. For simplicity we consider only the idea of a false retrospective accusation, say $p$, where the body $\beta_{p}$ expresses a proposition about the past. Then one may claim that falsity of the proposition coincides with falsity of the body $\beta_{p}$ as a proposition. Falsity is merely the negation of truth and truth of $\beta_{p}$ is a matter of subjective probability $P_{A}\left(\beta_{p}\right)$ which will be assessed by each agent $A$ independently. Thus $A$ 's belief in the falsity of $\beta_{p}$ equals $1-P_{A}\left(\beta_{p}\right)$.

Now $A$ may maintain a treshold of say $85 \%$ and require for the truth of an assertion $\alpha$ that $P_{A}(\alpha)>85 \%$. So we find that the accusation $p$ is true if $P_{A}\left(\beta_{p}\right)>85 \%$ and that the accusation $p$ is false if $1-P_{A}\left(\beta_{p}\right)>$ $85 \%$, that is $P_{A}\left(\beta_{p}\right) \leq 15 \%$.

This is an unsatisfactory outcome, first of all because the threshold of $15 \%$ is quite arbitrary and may not work for all cases, but secondly because unavoidably some certainty is suggested where none exists. It may be preferable for $A$ to contemplate a three valued logic with a modified (subjective) probability calculus. The terminology is best updated to speak of "considered false", "considered true", and "considered unresolved". Hepburn 2018 [31] suggests that members of the police force are still confusing "false" and "considered false".

The call for signatures issued by Dowell and Sobel in PEA Soup (the background being explained in [23]) supports the validity of the mechanism of accusee obstruction by trusters of trusted accusers of unconfirmable accusations. That principle raises various questions, one of which connects with subjective probability theory, and in particular the assignment of relatively high prior odds to some particular unconfirmed or even unconfirmable accusations. Combined retaliation by trusters of trusted accusers of unconfirmable accusations is considered legitimate by some authors in some cases. The specific type of case meant by the authors of the call considers the circumstance that the trusted accuser, accuses the accusee of episodes of sexual intimidation in private conditions thereby rendering attempts for confirmation futile. Now trust will replace confirmation thereby yielding legitimacy for acts of combined obstruction which consist of withholding the accusee "goodies" (that is, facilities and options) to which an accusee is not firmly entitled. An important argument raised in the Dowell-Sobel approach is the assumption that false accusations are rare. Nevertheless, the phenomenon of false accusations is not fictitious and may require yet more attention. On false accusations and in particular on conditions in which false accusations may arise we mention Hedges 2002 and Grattagliano et. al. 2014. Recent work (Ostrander 2018) on false accusations of sexual harassment focuses attention to matters of definition: a false accusation is understood as a provably false accusation. Thus unconfirmable accusations are not classified as false by definition. The latter state of affairs, however, is not yet well-understood by members of the police force.

The same confusion seems to exist in the proposal of Dowell-Sobel, where it is suggested that false accusations of sexual harassment are a marginal problem, thereby ignoring the fact that accusations which are "considered unresolved" and which are nevertheless held against the accused are just as deeply problematic.

Considering once more the Dowell-Sobel mechanism: if an accusation of sexual harassment is proven then the mechanism is unnecessary because ordinary disciplinary measures can be taken. If the accusation is false (where that means provably false), there is no issue either, because the obstructions allowed by the Dowell-Sobel mechanism should not be applied. It is precisely for accusations considered unresolved that problems remain, and counter to what is suggested that may be a majority of the cases.

The literature on false accusations has various branches. Three clusters of work stand out in this matter:

(i) There is a very extensive literature on false accusations of witchcraft. Such accusations are always false from a present day perspective, nevertheless witchcraft accusations have been ubiquitous and (unfortunately) still occur.

(ii) Then there is a significant literature on false accusations of various forms of abuse of children. The 
complexity of assessment of such accusations comes from the fact that the accuser may be third person (e.g. one of the parents accusing the other parent in a battle towards a divorce), as well as from the fact that obtaining reliable testimony from children is both highly non-trivial and controversial concerning admissible methods.

(iii) A third theme where false accusations play a central role concerns accusations of rape as well of other forms of sexual intimidation.

\subsection{Blame, charge and avowal}

Blaming and accusation are related concepts. The distinction seems to be this: when a person or an organisation $B$ is blamed for being in state $Q$ then the fact of the matter, that is, being in that state, and that fact being problematic as such is supposed to be given, that is, uncontested. The novelty requirement of the act of blaming lies in the very suggestion that behaviour of $B$ causally contributed to bringing the state $Q$ about.

A well-known form of blaming is victim blaming, which occurs when it is assumed that victims have causally contributed to their problems, even if pointing to a causal chain is a matter of pure speculation. A particular form of victim blaming is self-blame as an explanation or even justification of being victimized. Blaming can also take quite general and non-personal forms: for instance blaming EU citizens for hunger elsewhere. Specific for blaming is that the mechanism of causality is itself either novel or contested. So if a painting has been stolen from a museum by thieves who (i) were able to enter the museum during the night, (ii) open doors with proper keys, and (iii) managed to switch off alarms with adequate codes, then museum staff may be blamed for having been careless with security relevant equipment and data, but not for having actually stolen the painting. Claiming the latter would in this case constitute an accusation rather than an instance of blaming.

Komter 1994 [35] distinguishes everyday accusations from formal accusations, often called charges which take place at the beginning of a lawsuit. Komter indicates how a charge may consist of a sequence of increasingly serious accusations each describing the same event or state of affairs. It is then up to the court to determine which one of these, if any, can be considered proven. The charge (at least in The Netherlands where the idea of a plea bargain is absent), may take the form of a hyper-accusation which proactively takes into account various conceivable paths of defense.

An avowal (due to Foucault [24] is a promise which is not framed as an accusation but rather as the avower's perspective on a state of affairs. Avowal creep takes place if during an exchange of avowals, the claims made in such promises get stronger and closer to accusations while avoiding the corresponding framing.

\section{Concluding remarks and options for further work}

It is not the aim of this paper to present a full-blown theory of accusation but rather to outline a basic account of accusation as a prerequisite for further investigations. We differentiated (with help from Promise Theory) the following structural aspects: (i) a source, (ii) one or more targets, (iii) a collection of agents in scope, and (vi) a body (the content of the speech act) as components of a variety of possible spech acts: promise, threat, imposition, accusation, avowal, charge, blame, congratulation, condolence (discongratulation), complaint, warning, sign of happiness, sign of unhappiness, praise, dispraise. We claim that one should first interpret accusations as a speech act on the basis of those distinctions before other frameworks are applied. An important insight from the parallel with Promise Theory is the following assumption: The key idea of Promise Theory is that promises primarily provide a mechanism for bringing about voluntary cooperation between agents. In that understanding it is not constitutive for the speech act of a promise that the person 
who gives a promise is willing to keep the promise. That we may have strong moral reasons to keep promises is another matter that should be distinguished from the interpretation of what a promise is. Likewise, it is not constitutive for the understanding of accusations that accusers are willing to validate the accusation.

The rationale for the aim of accusing someone can, however, not be determined so easily since there seems to be huge diversity of practices in which accusations play a pivotal role. It seems to be a characteristic for accusations that there is an entire range of possible reasons why someone is accusing someone else and in many cases it is not obvious right from the beginning which the relevant reasons (or combinations of reasons) are. Because of this diversity the interpretation and as well the evaluation of accusations is such a demanding enterprise. To avoid misunderstandings: our claim that an initial identification of 'accusations' should be agnostic regarding the question whether or not accusers are willing to validate their accusation should not be confused with the empirical assumption that all (or most or even some) accusations are unfounded. Our claim has nothing to do with any empirical assessments about the prevalence or probability of wrong accusations. But we assume that wrong accusations are possible and that it is of utmost importance that procedures take this possibility into consideration. It is important for the accused but likewise for the reputation of the accuser and for the social dynamics around them. This initial understanding of accusations give raise to a variety of follow-up questions, we will only mention two of them: A first cluster of questions concerns the social dynamics around accusations in various social and institutional contexts. Which factors hinder or encourage the articulation of accusation? What are the social expectations accusers and accused are confronted with? What is the effect of formal procedures of dealing with accusations? How is the relationship between formal and informal forms of dealing with accusations? All those dynamics can be analysed without necessarily taking a stance regarding the validity of the accusations. A second and distinct cluster of questions concerns the normativity of accusations. Under which conditions should there be a duty to install formal procedure for accusations and under which standards should they be investigated? Different ethical theories and different political systems have different positions in this regard. A specific question arises how open societies (with a commitment to rule of law and human rights) should answer these questions. Prosecution of rights-violations is of central importance for those societies and therefor the opportunities of victims to make accusations public. At the same time is it pivotal for those societies to protect accusees against wrong accusations and to limit the possibility of topics that may be issued in the public domain. These matters ask for further scrutiny.

Another line of work is to investigate the form and role of accusations in a specialised context. Here only three examples for possible further investigations will be mentioned:

Accusation theory in the context of software quality. Consider software supplier (programmer) A who has written a program (for which an instruction sequence is used as a theoretical model) X for B. Suppose further that after having done some experiments with $\mathrm{X}$, or perhaps after having made some practical use of $\mathrm{X}, \mathrm{B}$ accuses A of having delivered an instruction sequence which contains one or more faults. Accusation theory in connection with software quality allows to design a context where some additional constraints are expected from (imposed on) an accuser, for instance in the case of the accusation just mentioned, that it is expected from B that they are able and willing to provide (i) a definition of an instruction sequence fault and (ii) that they are able and willing to provide references for that notion of fault or, (iii) if the notion of fault envisaged by B happens to be novel, to explain why introducing a novel notion of fault is considered plausible. For a survey of notions of software fault see [6]. Suppose $C$ has been tasked with testing $X$ and $\mathrm{B}$, being dissatisfied with the resulting instruction sequence $\mathrm{X}$, may accuse $\mathrm{C}$ of having left undetected too many dormant faults. Now, in the context of accusations about software quality it may be asked of $\mathrm{C}$ to clarify what a dormant fault is and what it means for a dormant fault to be detected. Related considerations apply if B merely accuses A of its product (i.e X) being defective, without claiming the presence of faults.

Related to accusations about software quality are accusations about informational money being stolen, a kind of event which is communicated in the public media every now and then. Now consider the case of 
informational money, and of Bitcoin in particular. Suppose that $A$ accuses $B$ of having stolen an amount of 1.5 Bitcoin from $C$. Following the theory of Bitcoin as an exclusively informational money (see e.g. Bergstra \& de Leeuw) [15] and Bergstra \& Wijland [16], this state of affairs is simply incoherent, it cannot be the case. Bitcoin cannot be stolen.

Accusations and the Extinction Rebellion (XR) movement. XR has rapidly obtained prominence since spring 2018. XR endorses a core accusation: governments have not complied with the social contract which requires them to take care of future generations. Therefore, XR considers it admissible to apply civil disobedience for disruption under the assumption that doing so contributes to the more external goal of creating awareness concerning climate problems and ecology. At the same time XR discourages naming and shaming, that is, turning climate worries and ecological concerns into accusations directed to a single person, or to a small group of individuals. The role of accusations in the meta-theory of XR is intriguing and merits further research.

Harassment by accusation. Accusations can be used as a means of harassment. HBA (for harassment by accusation; for some further comments on HBA one may inspect tweets accessible via the Twitter tag \#harbyacc) a mechanism which may well remain undetected unless special attention is paid to it. Self-defence against HBA may be extremely challenging. We expect that dedicated contextualisation of accusations in the context of HBA is rewarding. In particular the evolution of accusations through increasingly powerful repetition is a key mechanism, where damage by intentionally unproven accusations is done slowly and systematically without the target being able to organise any timely self-defence. We consider HBA to constitute extremely problematic behaviour, which can definitely be observed in (academic) practice. In HBA there is ample room for unfounded accusations for which no proof or disproof can be obtained. The relevant mechanisms have to be studied.

These are only some examples - it is easy to develop a much longer list of themes where accusations may play a central role. One has to be aware that the social dynamics that arose in the last couple of years in various societies and that is characterised by mistrust, hate speech and conspiracy thinking has an enormous impact on current societies. Accusations are a central element in these social dynamics. Dealing with accusation in a transparent manner is from utmost importance for the possibilities of societies to deal with diverging views in a rational manner.

Acknowledgements. Jan Bergstra acknowledges many discussions with Mark Burgess about the various perspectives of extending Promise Theory. Marcus Düwell acknowledges useful comments by Gesa Lindemann and Paul Ziche.

\section{References}

[1] Gregor Aisch, Jon Huangell and Cecilia Kang. Dissecting the \#PizzaGate conspiracy theories. NY Times, http://www.nytimes.com/interactive/2016/12/10/business/ media/pizzagate.html, (2016).

[2] Kevin Arseneaux and Rory Truex. Donald Trum and the lie? https: / / psyarxiv. com/e89ym (2021).

[3] Deryck Beyleveld, Marcus Düwell and Andreas Spahn. How should we represent future generations in policy making? Jurisprudence 6 (3), 549-566, (2015).

[4] David A. Baldwin. Thinking about threats. The Journal of Conflict Resolution, 15 (1), 71-78, (1971). 
[5] Jan A. Bergstra. Adams Conditioning and Likelihood Ratio Transfer Mediated Inference. Scientific Annals of Computer Science, 29 (1),1-58 (2019).

[6] Jan A. Bergstra. Instruction sequence faults with formal change justification. Scientific Annals of Computer Science 30 (2), pp. 105-166 (2020).

[7] Jan A. Bergstra. Promise theory as a tool for informaticians. Transmathematica, (2020). https: //doi.org/10.36285/tm.35

[8] Jan A. Bergstra. Promises in the context of humanoid robot morality. International Journal of Robotic Engineering , (2020). DOI: 10.35840/2631-5106/4126. https://vibgyorpublishers.org/ content/ijre/ijre-5-026.pdf

[9] Jan A. Bergstra. Promises and Threats by Asymmetric Nuclear-Weapon States. $\chi t$ Axis Press. ISBN: 978167318215, (2019).

[10] Jan Bergstra and Mark Burgess. Promise Theory: Principles and Applications. $\chi t$ Axis Press. ISBN: 9781495437779, 2014; Second edition ISBN: 9781696578554, (2019).

[11] Jan Bergstra and Mark Burgess. Promise Theory: Case Study on the 2016 Brexit Vote. $\chi t$ Axis Press. ISBN: 9781974545339 (2017).

[12] Jan Bergstra and Mark Burgess. Money, Ownership, and Agency. $\chi t$ Axis Press. ISBN9781696588379, (2019).

[13] Jan Bergstra and Mark Burgess. A promise theoretic account of the Boeing 737 Max MCAS algorithm affair, [cs.OH] (2019). https: / / arxiv.org/abs/2001.01543v1

[14] Jan Bergstra and Mark Burgess. Candidate software process flaws for the Boeing 737 Max MCAS algorithm and a risk for a proposed upgrade, [cs.CY] (2020). https: / / arxiv. org/abs/2001. 05690v1

[15] Jan Bergstra and Karl de Leeuw. Bitcoin and beyond: Exclusively Informational Monies, version 3, (2013). https://arxiv.org/abs/1304.4758v3

[16] Jan Bergstra and Peter Weijland. Bitcoin: a Money-like Informational Commodity, (2014). https: //arxiv.org/abs/1402.4778

[17] Lucy Berliner and Elisabeth Loftus. Sexual abuse accusations desperately seeking reconciliation. Journal of Interpersonal Violence, 7 (4): 570-578 (1992).

[18] Mark Burgess. A Treatise on Systems, Volume II: Intentional Systems with Faults, Errors, and Flaws. $\chi t$ Axis Press. (2017-2019).

[19] Mark Burgess. Thinking in Promises: Designing Systems for Cooperation. O'Reilly Media (2015).

[20] Campaign Legal. Compiling the truth: A resource to refute Trump's "Stolen Election" lies. https://campaignlegal.org/update/ compiling-truth-resource-refute-trumps-stolen-election-lies (2021).

[21] Erik Claes. Deconstruction, criminalisation and the criminal law: a reply to Pavlich's 'The lore of criminal accusation'. Criminal Law and Philosophy, 1, pp. 99-105 (2007). 
[22] Richard Craswell. Contract law, default rules, and the philosophy of promising. Michigan Law Review. 88 (3), 489-529, (1989).

[23] Janice Dowell and David Sobel. Sexual harassment in philosophy, Part 2. Daily Nous, news for and about the philosophy profession, September 5 (2009). https://dailynous.com/2019/09/ 05/sexual-harassment-philosophy-part-2-dowell-sobel/

[24] Michael Foucault. 1981 Lecture series at the Catholic University of Louvain. In: Wrong-doing, truthtelling: the function of avowal in justice, F. Brion, B.E. Harcourt, eds. The University of Chicago Press (2014).

[25] Gerd Fritz. On answering accusations in controversies. In: Argumentation in Dialogical Interaction, pp 151-162 (2005)

[26] Alan Gewirth. Human rights and future generations. In: M. Boylan (ed.): Environmental Ethics, Prentice Hall, 207-212, (2001).

[27] René Girard. La violence el le sacré. Paris: Grasset (1972), (English translation: Violence and the sacred. Translated by Patrick Gregory. Baltimore: John Hopkins University Press, 1977).

[28] Nathan E. Goldstein et. al. Prevalence of formal accusations of murder and euthanasia against physicians. Journal of Palliative Medicine, 15 (3),: 334-339 (2012).

[29] Ignazio Grattagliano et. al. False accusations of sexual abuse as a mean of revenge in couple disputes. La Clinica terapeutica, 165 (2): 119-124 (2014).

[30] Lawrence E. Hedges. False accusations: genesis and prevention. American Journal of Psychotherapy, 56 (4): 494-507 (2002).

[31] Alexa Hepburn. Power lines: Derrida, discursive psychology and the management of accusations of teacher bullying. British Journal of Psychology, 39: 605-628 (2000).

[32] Geoffrey Hughes, Megnaa Mehtta, Chiara Brescani and Stuart Strange. Ugly emotions and the politics of accusation. The Cambridge Journal of Anthropology. Volume 37, Number 2, Autumn 2019: 1-20 doi:10.3167/cja.2019.370202

[33] Quinn Javers. The logic of lies: false accusations and legal culture in late Qing Sichuan. Late Imperial China, 35 (2), pp 27-55, https: / / muse. jhu .edu/article/564699, (2014).

[34] John Kane. The long road down: how the party of Lincoln became the party of Trump. Social Alternatives, 40 (1), pp 10-20, https: / / muse. jhu.edu/article/564699, (2014).

[35] Martha L. Komter. Actions and defenses in courtroom interaction. Discourse and Society, 5 (2) pp. 165-187 (1994).

[36] Gesa Lindemann. Die Ordnung der Berürhung. Staat, Gewalt und Kritik in Zeiten der Corona-Krise. Velbrück Wissenschaft (2020).

[37] Berrtram F. Malle, Steve Guglielmo and Andrew E. Monroe. A theory of blame. Psychological Inquiry, 25: 1-40, (2014). 
[38] Olivia Nicol. The blame game for the financial crisis (2007-2010): a sociological theory of fields of accusation. European university institute, Max Weber Programme 2016. https : / cadmus . eui . eu/handle/1814/40728

[39] Danielle Ostrander. Police perceptions of false accusations of sexual assault. East Tenessee Stae University, Electronic Theses and Dissertations. Paper 3428, (2018). https://dc. et su . edu/ etd/3428

[40] George Pavlich. Forget crime: accusation, governance and criminology. Australian and New Zealand Journal of Criminology, 33 (2), pp 136-152 (2000).

[41] George Pavlich. The lore of criminal accusation. Criminal Law and Philosophy, 1, pp 79-97 (2006).

[42] George Pavlich. Avowal and criminal accusation. Law and Critique, 27, pp 229-245 (2016).

[43] George Pavlich. Before the law: criminalization, accusation and justice. Law and Critique, 28, pp 345-365 (2017).

[44] George Pavlich. Restorative justice and the rights of the accused. Restorative Justice, an International Journal, 5 (3), pp 396-407 (2017).

[45] Charles A. Pierce, Herman Aguinis and Susan K. Adams. Effects of dissolved workplace romance and rater characteristics on responses to a sexual harassment accusation. Academy of Management Journal. Vol. 3, No. 5, pp. 869-880 (2000).

[46] Jeffrey Richelson (ed.). Iraq and Weapons of Mass Destruction. National Security Archive Electronic Briefing Book No. 80, https: //nsarchive2.gwu. edu/NSAEBB/NSAEBB80/ (2004).

[47] Enzo Rossi. Facts, principles, and politics, (2014). Available at SSRN. http://dx.doi.org/ $10.2139 / \operatorname{ssrn} .2378366$

[48] Peter Rudiak-Gould. Climate change and accusation: global warming and local blame in a small island state. Current Anthropology, 55 (4): 365-385, (2014).

[49] Thomas Scanlon. Promises and practices. Philosophy and Public Affairs. 19 (3), 199-226, (1990).

[50] David Sobel. Call for signatures on sexual harassment statement. PEA Soup, October 2020, http://peasoup.us/2020/10/call-for-signatures-on-sexual-harassment-statement/

[51] Peter Tiersma and Lawrence Solan. The Oxford Handbook of Language and Law (2012), p. 291.

[52] Terrance Smith. Trump has a longstanding history of calling elections 'rigged' if he doesn't like the result. ABC News https://abcnews.go.com/Politics/ trump-longstanding-history-calling-elections-rigged-doesnt-results/ story?id=741269 (2020).

[53] Neal Tognazzinni and D. Justin Coates. Blame. In: The Stanford Encyclopaedia of Philosophy, ed. Edward N. Zalta, (2018). https: / plato.stanford.edu/archives/fal12018/entries/ blame/

[54] Joleen Traynor. Supreme court justice Brett Kavanaugh and accusations of sexual assault in the media. Political Analysis, 20, article 4, (2019). 
[55] Lindsey Webb. The immortal accusation. Washington Law Review, 90 (4), (2015). https: //digitalcommons.law.uw.edu/wlr/vol90/iss4/7

[56] Wikipedia on post election lawsuits, Accessed 20 July 2021. https://en.wikipedia. org/wiki/Post-election_lawsuits_related_to_the_2020_United_States_ presidential_election

[57] Wikipedia on Pizzagate. Accessed 20 July 2021: https://en.wikipedia.org/wiki/ Pizzagate_conspiracy_theory 